\title{
Characteristics of flow production and sediment production of Pinus tabulaeformis through artificial rainfall simulation
}

\author{
Yu-Li Zhao, Jian-Zhi Niu*, Jiao Li, Jing-Ping Tan, Yi-Ni Han, Ying-Hu Zhang \\ College of Water and Soil Conservation, Beijing Forestry University, Beijing, China; ${ }^{*}$ Corresponding Author: nexk@bjfu.edu.cn
}

Received 18 February 2012; revised 20 March 2012; accepted 12 April 2012

\begin{abstract}
In order to know well the relationship between vegetation and water in North China, especially Beijing, with exceptional water resources, we studied the characteristics of flow production and sediment production under different rainfall intensities by artificial rainfall simulation device. Results showed that increase of rainfall intensity would prolong the whole process of flow production, and vegetation on the slope would delay that process. Within the same duration, total runoff volume of each runoff plot and rainfall intensity had significant linear relationship. When vegetation kept unchanged, runoff velocity increased significantly with the increase of rainfall intensity, and owing to the formation of low permeable layer, the velocity increased fiercely during the early 3 minutes, reached stable at 10 15 minute. With the same rain intensity, total sediment yield decreased with rise of vegetation coverage, but increased obviously with rise of rain intensity and effectiveness of controlling sediment about $1 \mathrm{~m} \times 1 \mathrm{~m}$ Pinus tabulaeformis stand decreased firstly and then increased, while that about $1.5 \mathrm{~m} \times 1.5 \mathrm{~m}$ Pinus tabulaeformis stand kept decreasing. Since the tags with $A, B$ and $C$ for $0.42 \mathrm{~mm} / \mathrm{min}, 0.83 \mathrm{~mm} / \mathrm{min}$, $1.29 \mathrm{~mm} / \mathrm{min}$, order of sediment concentration of wasteland plot was $B>C>A$, and $1 \mathrm{~m} \times 1 \mathrm{~m}$ Pinus tabulaeformis plot $B>A>C$. Through this study, some suggestions were expected to be provided for water balance of Beijing area and certain basis for construction of shelter forest.
\end{abstract}

Keywords: Pinus tabulaeformis; Artificial Rainfall Simulation; Rainfall Intensity; Runoff Volume;

Sediment Yield

\section{INTRODUCTION}

Beijing is located in the lower of earthy and rocky mountainous area in North China, core region of Jingjin-ji Economic District. The economic development is rapid and it has dense population with insufficient water and soil resources [1]. As China's capital, soil and water loss in Beijing is serious. After decades of work, the area of soil and water loss water was still $4088.91 \mathrm{~km}^{2}$, which reduced the fertility in soil, damaged the landscape, deposited sediment in reservoir and blocked watercourse, also caused flooding and debris flow which threated the people's life and property security. All of these harms restricted economic development of Beijing mountain area seriously [2]. In addition, Beijing mountain area has severe leakage and less surface runoff, short of water. It would be easy to generate runoff and deep infiltration which could cause partial mountain landslide or earthrock sloughing [3]. Then relationship between vegetation and water seems particularly important. Therefore, research of the characteristics of soil and water loss under the condition of the existing vegetation in Beijing mountain area has an important meaning. However, annual rainfall of North China was low and it had scarce precipitation every year, thus times of runoff producing was few and corresponding data collected from fixed runoff plots which relied on natural rainfall was little. Besides, study based on natural rain cost more time. To mend these defects, we studied the characteristics of flow production and sediment production under different rainfall intensities with the method of artificial rainfall simulation which could get some data more quickly and effectively. Through that, basic data and theoretical basis were expected to be provided for future construction of protective forest system.

\section{STUDY AREA}

Runoff plots were set in the field Forest Experimental station of Beijing Forest University-Jiufeng National Forest Park in Beijing $\left(116^{\circ} 28^{\prime} \mathrm{E}, 39^{\circ} 54^{\prime} \mathrm{N}\right)$. The park is 
located in the town of Sujiatuo, Haidian District of Beijing, west of the North China plain. The climate is continental climate of the warm temperate zone of north China, hot in summer and more rain while winter is cold and dry. The highest temperature is $39.7^{\circ} \mathrm{C}$, the lowest $-19.6^{\circ} \mathrm{C}$, and the average $12.2^{\circ} \mathrm{C}$. Average rainfall is 630 $\mathrm{mm}$ while the evaporation capacity about $1800 \mathrm{~mm}$, and rain happens mostly in month of 6 - 9, which accounts for about $70 \%-80 \%$ of the annual rainfall [4]. Soil type between altitude of $70 \mathrm{~m}$ to $900 \mathrm{~m}$ is mountainous leaching brown soil [5]. Plant formation belongs to the warm temperate zone deciduous broadleaved forest mainly built in the 1960s. The main species include Platycladusorientalis, Quercus variabilis Blume, Robinia pseudoacacia L, Pinus tabulaeformis, Acer elegantulum, etc. We chose Pinus tabulaeformis - one of the main afforestation tree species in Beijing mountain area as our study object.

\section{MATERIAL AND METHOD}

\subsection{Study Apparatus}

The artificial rainfall simulator was manufactured by Beijing Jiaotong University and Beijing Normal University. The height of its nozzle was above 2.5 meters, and raindrops could get terminal velocity if they reached the ground. With different swing frequency of the nozzle of this device, we can simulate 10 levels of rainfall intensity range from $20 \mathrm{~mm} / \mathrm{h}$ to $200 \mathrm{~mm} / \mathrm{h}$ [6]. In the test, the third gear with single pendulum, the third gear with double pendulum and the fourth gear with double pendulum were selected with their practical value of $0.42 \mathrm{~mm} / \mathrm{min}$, $0.83 \mathrm{~mm} / \mathrm{min}, 1.29 \mathrm{~mm} / \mathrm{min}$, respectively. The choice of the gears was based on the artificial rainfall simulator and some rainfall data about the study area [7-8]. In addition, for analysis of relationship between vegetation and runoff, we needed to have data about runoff, so the chosen rainfall intensities were greater to generate runoff. Stable rainfall intensity, perfect rainfall uniformity (all above $80 \%$ ), similar to raindrop distribution of natural rainfall, stable performance and convenient operation were the device's advantages.

\subsection{Study Method}

Marked an area of $210 \mathrm{~cm} \times 450 \mathrm{~cm}$-runoff plot, with several iron sheets on the slope with new forestation by $1 \mathrm{~m} \times 1 \mathrm{~m}$ and $1.5 \mathrm{~m} \times 1.5 \mathrm{~m}$ Pinus tabulaeformis stand, also wasteland slope, but kept the slope gradient consistent. Before each rain, basic situation of vegetation and soil antecedent water content should be recorded. And to reduce the influence of natural factors, rainfall time was generally chosen in sunny morning without wind. Every time, soil antecedent water content should be almost the same. During the rain, recorded time that began to produce flow and stopped producing flow, each rain lasted 60 minutes. After the rain, measured runoff volume and sediment yield in runoff barrel respectively.

\section{RESULTS ANALYSIS}

\subsection{Characteristics of Flow Production under Different Rainfall Intensities}

Vegetation, rainfall intensity, slope gradient, soil moisture content are important factors which influence runoff start time [9]. It is observed in Figure 1 that starts time of runoff about wasteland slope and slopes with vegetation all decreased as rainfall intensityincreased, yet the former was less than the latters. Figure 2 shows that end time of runoff increased with rainfall intensity, and the value of wasteland slope was less than that of slopes with vegetation. These facts showed that both rainfall intensity and vegetation would affect characteristics of flow production [10-12], and with the same rainfall time, whole process of flow production would prolong along with increase of rainfall intensity, and vegetation on the slope would make this process begin later.

It can be summarized from Figure 3 that rainfall intensity greatly influenced total runoff volume, they were

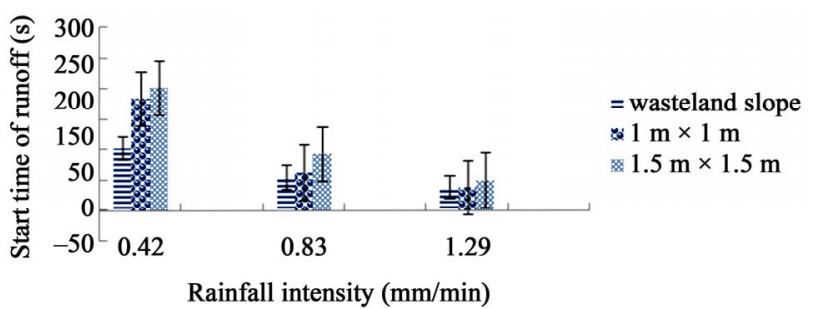

Figure 1. Change of runoff start time.

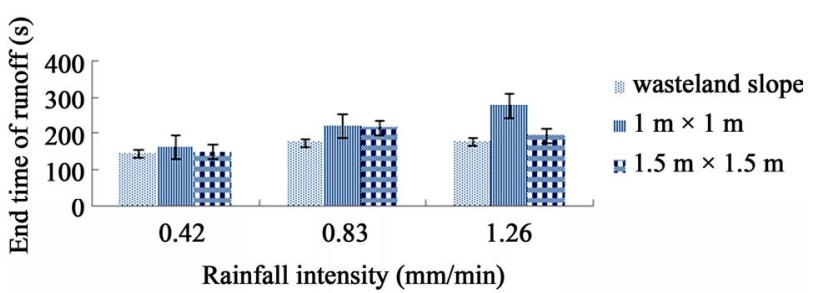

Figure 2. Change of runoff end time.

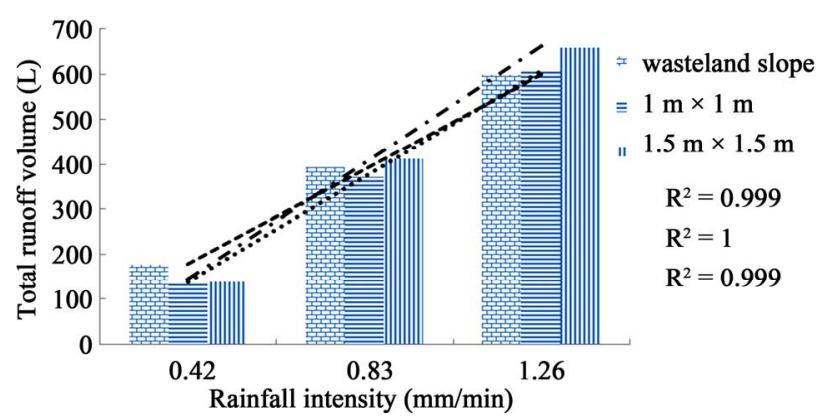

Figure 3. Total runoff volume under different rainfall intensities. 
positively related, and the linear relationship was very significant $\left(\mathrm{R}^{2}>0.999\right)$. Total runoff volume of $1.5 \mathrm{~m} \times$ $1.5 \mathrm{~m}$ Pinus tabulaeformis plot was more than that of 1 $\mathrm{m} \times 1 \mathrm{~m}$. But compared with wasteland plot, when rainfall intensity was $0.42 \mathrm{~mm} / \mathrm{min}$, runoff volume of $1 \mathrm{~m} \times$ $1 \mathrm{~m}$ and $1.5 \mathrm{~m} \times 1.5 \mathrm{~m}$ Pinus tabulaeformis were less than volume of wasteland plot. Instead, along with increase of rainfall intensity, runoff volumes of plots with vegetation were more, which was contradictory to the general conclusions that vegetation could control loss of soil and water [13-14]. So it is necessary to further explore the effect of integrated factors such as rainfall intensity and vegetation coverage on law and mechanism of soil and water loss.

Figure 4 shows that, when coverage degree kept constant, runoff velocity increased significantly with rise of rainfall intensity. Under different rainfall intensities, similar rule was presented as average runoff velocity on the slope changed with time: in early time, especially the first 3 minutes, runoff velocity increased sharply, and the greater the rainfall intensity, the stronger increase degree. When it was about 10 - 15 min, velocity began to keep stable. The reason was that in initial phase of rain, raindrop reached the ground and scattered soil aggregate. Then dispersed particles accumulated and plugged water infiltration route, and a layer with very low-permeability formed [15]. That layer made most rainfall change into overland runoff, and the greater rainfall intensity the more severe aggregate scattered, infiltration channels would be blocked faster. That means more rainfall reached the ground in certain time and less time taken to produce runoff, and result of these led to greater growth of runoff rate.

\subsection{Characteristics of Sediment Production under Different Rainfall Intensities}

It is clear (Figure 5) that sediment yield increased obviously with rainfall intensity, because with the increase of rainfall intensity, much more raindrops reached the surface in unit time which means stronger total kinetic energy, greater impact on the surface, more fine soil particles and more material source provided for sediment. In addition, in the same rainfall condition, the order of sediment yield of three runoff plots was: wasteland $>1.5$ $\mathrm{m} \times 1.5 \mathrm{~m}$ Pinus tabulaeformis $>1 \mathrm{~m} \times 1 \mathrm{~m}$ Pinus tabulaeformis. The result was consistent with that of Hudson [16] - insufficient vegetation density can cause severe soil erosion. It was also similar to result of studies on the configuration and function of different density Pine in Beijing mountain area by Lu Shao-wei [17]. Because sand moved with water. Along with the increase of vegetation coverage, amount of canopy interception and role of reducing energy of raindrops both increased, which resulted in less rainfall with reduced energy. Then the ability to carry sediment was inevitably weak.

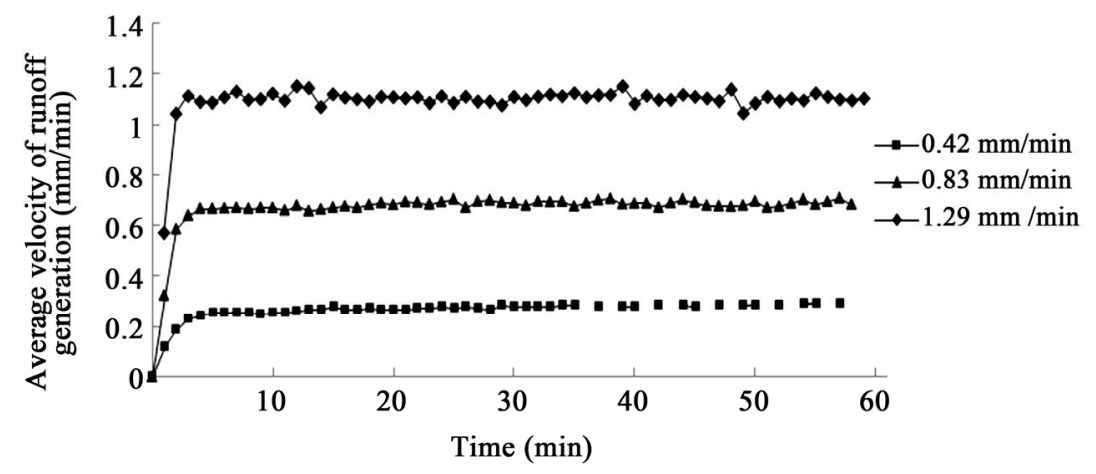

Figure 4. Change of runoff velocity about $1 \mathrm{~m} \times 1 \mathrm{~m}$ Pinus tabulaeformis under different rainfall intensities.

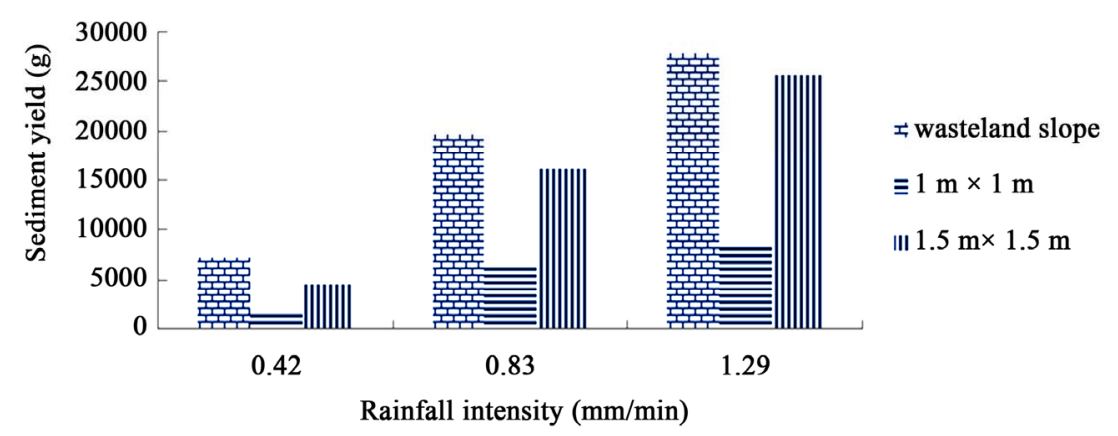

Figure 5. Sediment yield under different rainfall intensities. 
Table 1 reveals that $1 \mathrm{~m} \times 1 \mathrm{~m}$ Pinus tabulaeformis stand was more effective than $1.5 \mathrm{~m} \times 1.5 \mathrm{~m}$ Pinus tabulaeformis stand to control sediment yield. The two plots, whose coverage was $42.65 \%$ and $19.19 \%$ respectively, as rainfall intensity increased, effectiveness of controlling sediment of the former first decreased and then increased, while the later kept decreasing.

\subsection{Relationship between Runoff Volume and Sediment Yield under Different Rainfall Intensities}

It is observed in Figures 6 and 7 that sediment concentration in runoff of slope with plant was signifycantly less than that of wasteland slope [18]. When rainfall intensity was $0.83 \mathrm{~mm} / \mathrm{min}$, sediment concentration of wasteland plot could be as high as $110.36 \mathrm{~g} / \mathrm{L}, 1 \mathrm{~m} \times 1$ $\mathrm{m}$ Pinus tabulaeformis $36.63 \mathrm{~g} / \mathrm{L}$, by contrast. The reason is that if there was some vegetation on the slope, the canopy could intercept part of rainfall, avoid direct touch of raindrop and the ground as well, which reduced impact on surface soil [19]. Some researchers had the conclusion that sediment changed with runoff volume [20-21]. Based on relationship between runoff and rainfall intensity mentioned above, sediment concentration should increase as rainfall intensity. However, in our test, no matter if there was vegetation, sediment concentration was generally the highest when rainfall intensity was $0.83 \mathrm{~mm} / \mathrm{min}$. Since the tags with A, B and C for 0.42 $\mathrm{mm} / \mathrm{min}, 0.83 \mathrm{~mm} / \mathrm{min}, 1.29 \mathrm{~mm} / \mathrm{min}$, order of sediment concentration of wasteland plot was $\mathrm{B}>\mathrm{C}>\mathrm{A}$, and $1 \mathrm{~m}$ $\times 1 \mathrm{~m}$ Pinus tabulaeformis plot B $>\mathrm{A}>\mathrm{C}$.

\section{CONCLUSIONS AND DISCUSSION}

1) Within the same rainfall duration, increase of rainfall intensity would prolong the whole process of flow production by reducing initial runoff start time and increasing delayed runoff end time, and vegetation on the slope would make it later.

2) Within the same duration, total runoff volume of each plot and rainfall intensity had significant linear relationship. However, it is needed to further explore the effect on law and mechanism of soil and water loss of integrated factors such as rainfall intensity and vegetation coverage.

3) When vegetation kept unchanged, runoff velocity increased significantly with increase of rainfall intensity. Besides, under different rainfall intensities, owing to formation of low-permeable layer, similar rule was presented as average runoff rate on the slope changed with the passage of time: runoff velocity increased fiercely during the early 3 minutes, reached stable at 10-15 minute.

4) Under the same rainfall condition, order of sedi- ment yield of all runoff plots was that wasteland $>1.5 \mathrm{~m}$ $\times 1.5 \mathrm{~m}$ Pinus tabulaeformis $>1 \mathrm{~m} \times 1 \mathrm{~m}$ Pinus tabulaeformis. As rainfall intensity increased, sediment yield of each plot increased obviously, and effectiveness of controlling sediment of $1 \mathrm{~m} \times 1 \mathrm{~m}$ Pinus tabulaeformis decreased firstly and then increased, while $1.5 \mathrm{~m} \times 1.5 \mathrm{~m}$ Pinus tabulaeformis kept decreasing. Which meant both rainfall intensity and stand density were factors that affected soil erosion. Therefore, we should construct shelter forest system according to local site conditions and rainfall condition and have a good plan for stand density.

5) Sediment concentration in runoff of slope with plant was significantly less than that of wasteland slope. With tags $\mathrm{A}, \mathrm{B}$ and $\mathrm{C}$ for $0.42 \mathrm{~mm} / \mathrm{min}, 0.83 \mathrm{~mm} / \mathrm{min}, 1.29$ $\mathrm{mm} / \mathrm{min}$, order of sediment concentration of wasteland plot was $\mathrm{B}>\mathrm{C}>\mathrm{A}$, and $1 \mathrm{~m} \times 1 \mathrm{~m}$ Pinus tabulaeformis plot $\mathrm{B}>\mathrm{A}>\mathrm{C}$.

Table 1. Effectiveness of controlling sediment under different rainfall intensities.

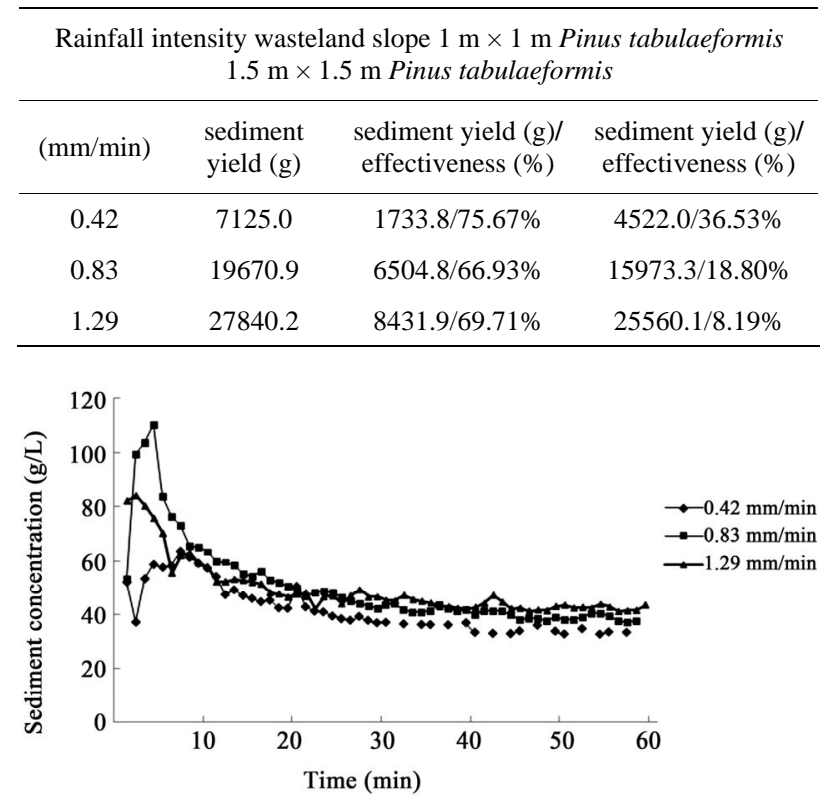

Figure 6. Change of sediment concentration in runoff of wasteland slope with time.

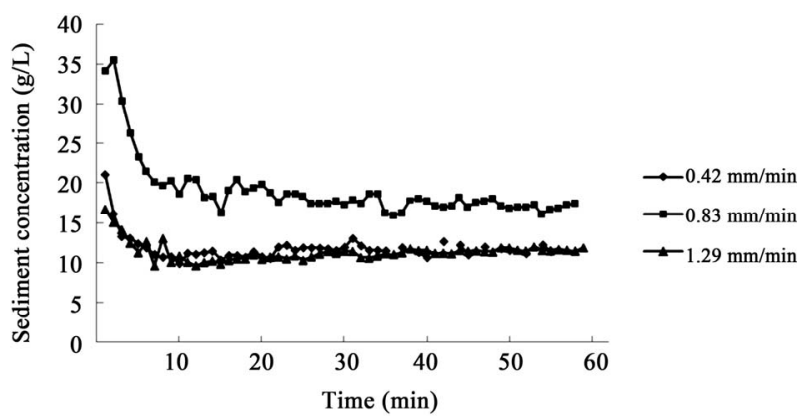

Figure 7. Change of sediment concentration in runoff of $1 \mathrm{~m} \times$ $1 \mathrm{~m}$ Pinus tabulaeformis with time. 


\section{ACKNOWLEDGEMENTS}

This study was financially supported by the National Special Fund for the Commonweal Industry (201104005), Key Projects in the National Science\& Technology Pillar Program during the Twelfth Five-Year Plan Period (2011BAD38B05) and National Science Foundation of china (30800888).

\section{REFERENCES}

[1] Yang, X.-B., Song, Q.-F., Cao, Y.-S., et al. (2009) Study on management models of typical small watershed in mountain and rocky area of North China-Based on beizhuang small watershed. Journal of Soil and Water Conservation in China, 7, 10-12.

[2] Jin, H.-C. (2002) Soil and water loss and its prevention in Beijing. Journal of Beijing Water Resources, 2, 16-19.

[3] Xiao, Z.-X., Zhu, W.-L., Niu, J.-Z., et al. (2011) Soil preferential flow under different forest stands in Jiufeng National Forestry Park. Journal of Hunan Agricultural Sciences, 17, 118-121.

[4] Yan, M. (2005) Studies on ecological benefits evaluation in Jiufeng National Forest Park. PhD Thesis, Beijing Forestry University, Beijing.

[5] Wang, Y., Qiao, Y. and Sun, X.-Y. (2010) Soil taxonomy in Jiufeng National Forest Park. Beijing. Journal of Beijing Forestry University, 32, 217-220.

[6] Zhang, G.-H., Liu, B.-Y. and Li, P.-K. (2007) Principles and properties of artificial trough rainfall simulator. Journal of Bulletin of Soil and Water Conservation, 27, 56-60.

[7] Li, S.-Y. and Ma, J.-J. (2011) Impact of urbanization on precipitation in Beijing area. Journal of the Meteorological Sciences, 31, 414-421.

[8] Luo, D. (2008) Studies on the dynamic characteristics of rainfall under the forest in Beijing mountainous area. PhD Thesis, Beijing Forestry University, Beijing.

[9] Chen, H.-S., Shao, M.-A., Zhang, X.-C., et al. (2005) Field experiment on hillslope rainfall infiltration and runoff under simulated rainfall conditions. Journal of Soil Water Conservation, 19, 5-8.

[10] Wang, Y.-L., et al. (2011) Sediment and runoff yield characteristics of slope lands under different intensity of rainfall in southern region of Ningxia. Ningxia Journal of Agriculture and Forestry Science and Technology, 52, 6467.
[11] Duan, W.-B. and Liu, S.-C. (2006) Analysis on runoff and sediment yields of water conservation forests in Lianhua Lake reservoir area. Journal of Soil and Water Conservation, 20, 12-15.

[12] Zhou, H.-F., Wang, D.-Q., Ma J., et al. (2009) Impacts of grass coverage and rainfall intensity on runoff and sediment yield in Tianshan Mountains of China-A case study of the Tianchi Natural Lake reserve area. Journal of Bulletin of Soil and Water Conservation, 29, 26-29.

[13] Martínez Raya, A., Durán Zuazo, V.H. and FranciaMartínez, J.R. (2006) Soil erosion and runoff response to plant-cover strips on semiarid slopes (SE Spain). Land Degradation and Development, 17, 1-11. doi:10.1002/ldr.674

[14] Xu, X.-L., Ma, K.-M., Fu, B.-J., et al. (2006) Research review of the relationship between vegetation and soil loss. Journal of Acta Ecologica Sinica, 26, 3137-3143.

[15] Assouline, S. (2004) Rainfall-induced soil surface sealing: A critical review of observations, conceptual models, and solutions. Vadose Zone Journal, 3, 570-591. doi:10.2113/3.2.570

[16] Hudson, N.W. and Jackson, D.C. (1959) Results achieved in the measurement of erosion and runoff in Southern Rhodesia. Proceedings of the 3rd Inter-African Soils Conference, Dalaba, 2-11 November 1959, 1-15.

[17] Lu, S.-W., Feng, Q., Yu, X.-X., et al. (2008) Studies on the configuration and function of different density pine in Rocky Mountain area of Beijing. Journal of Research of Soil and Water Conservation, 15, 117-121.

[18] Li, P., Cai, W.-B., Zheng, L.-Y., et al. (2006) Effects of vegetative cover on runoff hydraulic characteristics and erosion. Journal of Science of Soil and Water Conservation, 4, 55-59.

[19] Qiao, G.-J., Tan, L.-G. and Chen, E.-Y. (2009) Experimental study on deceleration of soil erosion by watershed vegetation. Journal of Water Resources Protection, 25, 52-56.

[20] Huang, M.-B. and Liu, X.-Z. (2002) Regulation effect of forest vegetation on watershed runoff in the Loss Plateau. Chinese Journal of Applied Ecology, 13, 1057-1060.

[21] Li, M., Yao, W.-Y., Ding, W.-F., et al. (2005) Effect of grass coverage on sediment yield in the hillslope-gully side erosion system. Journal of Geographical Sciences, 60, 25-732. 